\title{
Evaluation of ECG Time Intervals in a Rabbit Model of Anthracycline-Induced Cardiomyopathy: A Useful Tool for Assessment of Cardioprotective Agents
}

\author{
A. POTÁČOVÁ, M. ADAMCOVÁ, H. ČAJNÁKOVÁ, L. HRBATOVÁ, \\ M. ŠTĚRBA, O. POPELOVÁ, T. ŠIMU゚NEK ${ }^{1}$, P. POŇKA ${ }^{2}$, V. GERŠL
}

Faculty of Medicine, ${ }^{1}$ Faculty of Pharmacy, Charles University, Hradec Králové, Czech Republic and ${ }^{2}$ Lady Davis Institute for Medical Research, McGill University, Montreal, Canada

Received September 18, 2006

Accepted January 4, 2007

\begin{abstract}
Summary
The aim of this study was to analyze the ECG time intervals in the course of the development of chronic anthracycline cardiomyopathy in rabbits. Furthermore, this approach was employed to study the effects of a model cardioprotective drug (dexrazoxane) and two novel iron chelating compounds - salicylaldehyde isonicotinoyl hydrazone (SIH) and pyridoxal 2-chlorobenzoyl hydrazone (o-108). Repeated daunorubicin administration induced a significant and progressive prolongation of the QRS complex commencing with the $8^{\text {th }}$ week of administration. At the end of the study, we identified a significant correlation between QRS duration and the contractility index $\mathrm{dP} / \mathrm{dt}_{\max }(\mathrm{r}=-0.81 ; \mathrm{P}<0.001)$ as well as with the plasma concentrations of cardiac troponin $\mathrm{T}(\mathrm{r}=0.78 ; \mathrm{P}<0.001)$. In contrast, no alterations in ECG time intervals were revealed in the groups co-treated with either dexrazoxane or both novel cardioprotective drugs (SIH, o108). Hence, in this study, the QRS duration is for the first time shown as a parameter suitable for the non-invasive evaluation of the anthracycline cardiotoxicity and cardioprotective effects of both well established and investigated drugs. Moreover, our results strongly suggest that novel iron chelators (SIH and o-108) merit further study as promising cardioprotective drugs against anthracycline cardiotoxicity.
\end{abstract}

Key words

Anthracyclines $\bullet$ Daunorubicin $\bullet$ Dexrazoxane $\bullet$ Iron chelator $\bullet$ ECG $\bullet$ Troponin T

Since the late 1960s, anthracycline antibiotics have been among the most effective and widely used antineoplastic agents. Unfortunately, their repeated administration is accompanied by the risk of severe dosedependent cardiotoxicity, which manifests itself as a left ventricular (LV) heart failure. Besides the typical abnormalities in LV contractility, the changes in cardiac electrophysiology have also been reported - mainly disturbances in ventricular depolarization and repolarization as well as a significant prolongation of the corresponding ECG intervals (van Acker et al. 1996, Noda et al. 1998). 
As the chronic type of anthracycline cardiotoxicity represents a serious and largely irreversible complication of chemotherapy, great effort has been dedicated to prevent its onset. To date, numerous different substances have been studied with the aim to prevent or reduce the anthracycline-induced cardiomyopathy. However, at present only dexrazoxane (DXZ), a bisdiketopiperazine iron-chelating agent has been found to be sufficiently effective and has been approved for clinical use. A product of intracellular hydrolysis of DXZ (ADR-925) probably reduces anthracycline cardiotoxicity by binding free or loosely bound intracellular iron, and thereby it prevents the formation of highly toxic hydroxyl radicals (Malisza and Hasinoff 1996). As the use of dexrazoxane suffers from certain disadvantages, other alternative agents with potentially cardioprotective effects are currently under study - among others aroylhydrazone iron chelators salicylaldehyde isonicotinoyl hydrazone (SIH) and pyridoxal 2-chlorobenzoyl hydrazone (o-108). Our previous studies have revealed no significant cardiotoxic side effects of these novel chelators as well as any changes of ECG (Adamcová et al. 2002, Šimůnek et al. 2005, Štěrba et al. 2005, 2006).

The present study aimed to analyze the changes in ECG intervals in the time course of the development of chronic anthracycline cardiotoxicity on a validated rabbit model (Geršl and Hrdina 1994, Šimůnek et al. 2004). Furthermore, this approach was employed to study cardioprotective effects of both the well established cardioprotectant (dexrazoxane) and two novel agents (SIH and o-108). The usefulness of ECG analysis in the experimental study of anthracycline cardiotoxicity has been indicated by various authors in different species. However, in rabbits there is the only study of DzielskaOlczak et al. (2004), which assessed the ECG changes in doxorubicin-treated rabbits and concluded that ECG alone does not always reflect heart damage and therefore should not be used as a sole evidence of cardiotoxicity.

All experiments were performed under the supervision of the Ethical Committee of the Faculty of Medicine in Hradec Králové. The study was carried out on Chinchilla male rabbits. All agents were given once a week for 10 weeks in following groups:

- control (saline, $1 \mathrm{ml} / \mathrm{kg}$ i.v.), $\mathrm{n}=11$

- $D A U$ (daunorubicin, Cérubidine, $3 \mathrm{mg} / \mathrm{kg}$ i.v.), $\mathrm{n}=15$

- $D A U$ + dexrazoxane (Cardioxane, $60 \mathrm{mg} / \mathrm{kg}$ i.p., 30 min before each DAU), $\mathrm{n}=5$

- $D A U+S I H$ (1 mg/kg i.v. in PEG 300/ethanol/saline, 10 min before each DAU), $n=8$
- $D A U+o-108(10 \mathrm{mg} / \mathrm{kg}$ i.p. in $10 \%$ Cremophor EL, 30 min before each DAU), $\mathrm{n}=8$

The electrocardiograms (standard bipolar leads) were recorded and evaluated using the ADI PowerLab/8SP and software Chart for Windows v. 3.4.11 (ADInstruments, Australia) at the beginning of the study and thereafter in selected time intervals (Fig. 1) before drug administration. Cardiac troponin $\mathrm{T}$ (cTnT) as a selective and sensitive marker of heart damage induced by chemotherapeutics (Adamcová et al. 1999, 2005) was determined in heparinized plasma using the Elecsys Troponin T STAT Immunoassay (Roche, Switzerland). All experiments were done under ketamine anesthesia (30 mg/kg i.m.). Invasive hemodynamic measurements of the left ventricular contractility index $\left(\mathrm{dP} / \mathrm{dt}_{\max }\right)$ were performed at the end of experiment under pentobarbital anesthesia (30 mg/kg, i.v.). The left carotid artery was prepared and a PE catheter, filled-in with heparinized $(10 \mathrm{IU} / \mathrm{ml})$ saline was introduced into the left heart ventricle. After a 15-minute equilibration period, the measurement of maximal rate of the pressure rise in the isovolumic phase of the systole $\left(\mathrm{dP} / \mathrm{dt}_{\max }\right)$ was performed using an ADI PowerLab 8SP apparatus (ADInstruments, Australia) with appropriate transducers. Statistical evaluation was performed with the statistical software SigmaStat for Windows 3.0 (Jandel, Germany). Significances of differences were assessed with One-way ANOVA or Kruskal-Wallis ANOVA on Ranks. Spearman Rank Order Correlation was used to determine strengths of association between the QRS duration and $\mathrm{cTnT}$ or $\mathrm{dP} / \mathrm{dt}_{\max }$.

No significant changes either in the heart rate or the PQ interval were observed in the experimental group during the whole experiment. Surprisingly, we failed to find any consistent significant alteration of QT interval, which seemed to be the most promising parameter from the literature. This may result from difficulties accompanying precise determination of the end of repolarization on ECG of rabbits. Indeed some other authors have described similar experience with ECG in other species, e.g. with dog having a very labile $\mathrm{T}$ wave and the rat having the ST segment short or nonexistent (Gad 1992).

However, repeated DAU administration induced a significant prolongation of the QRS complex starting at the $8^{\text {th }}$ week $(0.043 \pm 0.001 \mathrm{~s})$ as compared with both the initial value $(0.039 \pm 0.001 \mathrm{~s})$ and the control group $(0.038 \pm 0.001 \mathrm{~s})$ (Fig. 1). These findings corresponded well with other biochemical and functional parameters as 


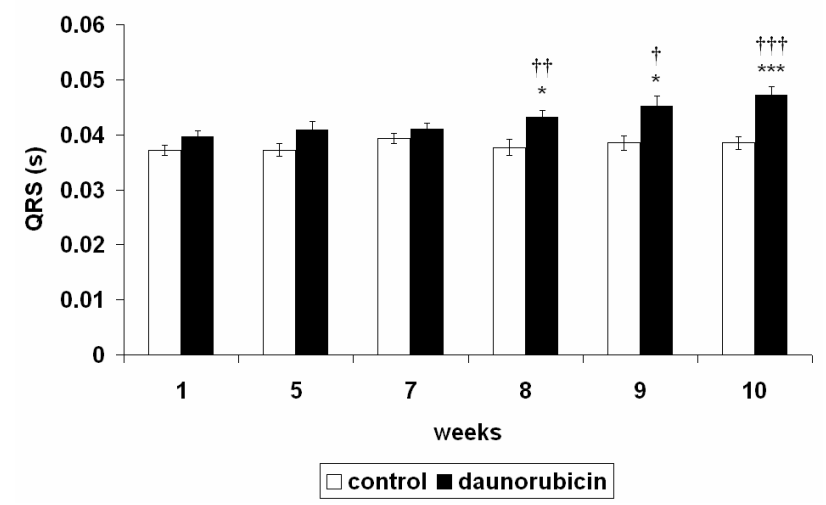

Fig. 1. Changes of the QRS duration during the experiment. *statistical significance in comparison with the initial values within each group (paired T-test; $\mathrm{P}<0.05$ ), $* * *$ (paired T-test; $\mathrm{P}<0.001)$, + statistical significance in comparison with the control group (T-test; $\mathrm{P}<0.05)$, $+\dagger(\mathrm{T}$-test; $\mathrm{P}<0.01)$, $+\dagger+(T$-test; $\mathrm{P}<0.001)$

previously described (Geršl and Hrdina 1994, Adamcová et al. 1999), showing that critical cumulative dose of anthracycline is reached in our model during the 8th week. At the end of experiment, the prolongation of QRS in DAU group reached $120.5 \pm 3.9 \%$ of the initial value, whereas in the control group only $103.5 \pm 2.6 \%(\mathrm{p}<0.05)$. On the contrary, the same ECG analysis, performed at the end of experiment, did not reveal any significant alteration of QRS duration in the groups co-treated with either the well established cardioprotectant dexrazoxane (108.1 $\pm 6.9 \%$; n.s.) or with our investigated compounds,

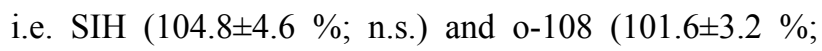
n.s.). The present findings are in accordance with other parameters under study, which is clearly shown by a good correlation between QRS complex and the left ventricular contractility index $\mathrm{dP} / \mathrm{dt}_{\max }(\mathrm{r}=-0.81 ; \mathrm{P}<0.001)$, as well as with the plasma concentrations of $\mathrm{cTnT}(\mathrm{r}=0.78$; $\mathrm{P}<0.001$ ) measured at the end of the experiment (Fig. 2).

In agreement with the ECG data, the left ventricular contractility $\left(\mathrm{dP} / \mathrm{dt}_{\max }\right)$ was significantly reduced in DAU-treated animals $(783 \pm 53 \mathrm{kPa} / \mathrm{s})$ compared to the control group $(1345 \pm 61 \mathrm{kPa} / \mathrm{s} ; \mathrm{P}<0.05)$. Furthermore, co-treatment with cardioprotective drugs led to a significantly higher contractility than in the DAU group and no significant difference was observed in comparison with the control group: dexrazoxane $(1411 \pm 77 \mathrm{kPa} / \mathrm{s}), \quad 0-108(1131 \pm 124 \mathrm{kPa} / \mathrm{s})$ and $\mathrm{SIH}$ $(1184 \pm 80 \mathrm{kPa} / \mathrm{s})$. In accordance with the ECG data, the last measured values of cTnT plasma levels during the experiment were significantly higher $(\mathrm{P}<0.05)$ in the DAUgroup $(0.33 \pm 0.05 \mathrm{ng} / \mathrm{ml})$ vs. controls $(0.02 \pm 0.01$ $\mathrm{ng} / \mathrm{ml})$. All groups with the cardioprotectants had the cTnT concentrations significantly lower $(\mathrm{P}<0.05)$ as
A

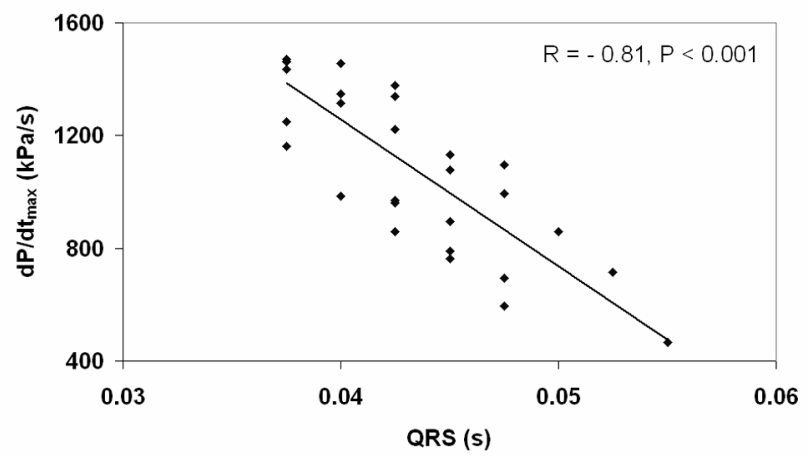

B

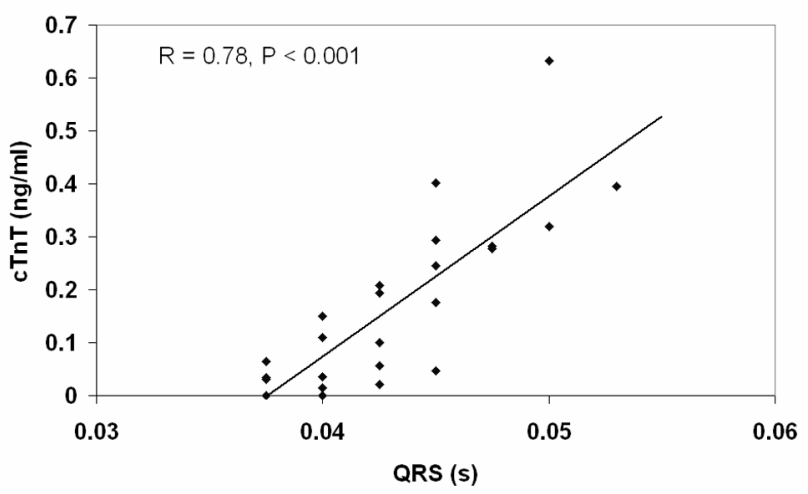

Fig. 2. A. Scatterplot of the left ventricular contractility (dP/ $\mathrm{dt}_{\max }$ ) versus QRS duration. B. Scatterplot of the plasma levels of cardiac troponin (cTnT) at the end of experiment versus QRS duration. $\mathrm{R}$ - correlation coefficient, $\mathrm{P}$ - statistical significance determined by Spearman's correlation analysis.

compared with the DAU group - DXZ $(0.04 \pm 0.02 \mu \mathrm{g} / \mathrm{l})$, o- $108(0.21 \pm 0.03 \mu \mathrm{g} / \mathrm{l})$ and $\operatorname{SIH}(0.22 \pm 0.05 \mu \mathrm{g} / \mathrm{l})$.

We can therefore conclude that for the first time, the analysis of the QRS duration, performed on the validated model in rabbits, was found to be a suitable marker of chronic anthracycline cardiotoxicity. Moreover, it was shown that it is a useful parameter for simple evaluation of cardioprotective effects of new investigated agents. Hence, this study suggests that detailed analysis of electrical properties of the myocardium may be a valuable part of the preclinical evaluation of potential cardiotoxic as well as cardioprotective effects of drugs. Importantly, our findings further support the concept of intracellular iron chelation as a successful strategy for the protection against anthracycline cardiotoxicity (Swain and Vici 2004). Both SIH and o- 108 were shown to be promising cardioprotective drugs which deserve further study.

\section{Acknowledgements}

This study was supported by the Research Project of MSM 0021620820. 


\section{References}

ADAMCOVÁ M, GERŠL V, HRDINA R, MĚLKA M, MAZUROVÁ Y, VÁVROVÁ J, PALIČKA V, KOKŠTEIN Z: Cardiac troponin $\mathrm{T}$ as a marker of myocardial damage caused by antineoplastic drugs in rabbits. $J$ Cancer Res Clin 125: 268-274, 1999.

ADAMCOVÁ M, MACHÁČKOVÁ J, GERŠL V, PELOUCH V, ŠIMŮNEK T, KLIMTOVÁ I, HRDINA R, POŇKA P: Cardiac troponin T following repeated administration of pyridoxal isonicotinoyl hydrazone in rabbits. Phys Res 51: 443-448, 2002.

ADAMCOVÁ M. ŠTĚRBA M, ŠIMŮNEK T, POTÁČOVÁ A, POPELOVÁ O, MAZUROVÁ Y, GERŠL V: Troponin as a marker of myocardiac damage in drug-induced cardiotoxicity. Expert Opin Drug Saf 4: 457-472, 2005.

DZIELSKA-OLCZAK M, GRACZYK-WOJCIECHOWSKA J, PAKULSKA W, ZIEBA R: Influence of doxorubicin and carnosine on the standard 12-lead electrocardiogram in rabbits. Acta Pol Pharmacol 61: 56-58, 2004.

GAD SH: Acute and chronic evaluation of the cardiovascular toxicity of drugs. In: Cardiovascular Toxicology ACOSTA D Jr (ed), Raven Press, New York, 1992, pp 21-43.

GERŠL V, HRDINA R: Noninvasive polygraphic changes in daunorubicin-induced cardiomyopathy in rabbits. Sbor véd prací LF UK Hradec Králové 37: 49-55, 1994.

MALISZA KL, HASINOFF BB. Inhibition of anthracycline semiquinone formation by ICRF-187 (dexrazoxane) in cells. Free Radic Biol Med 20: 905-914, 1996.

NODA T, WATANABE T, KOHDA A, HOSOKAWA S, SUZUKI T: Chronic effects of a novel synthetic anthracycline derivative (SM-5887) on normal heart and doxorubicin-induced cardiomyopathy in beagle dogs. Invest New Drugs 16: 121-128, 1998.

ŠIMU゚NEK T, BOER C, BOUWMAN RA, VLASBLOM R, VERSTEILEN AM, STERBA M, GERŠL V, HRDINA R, POŇKA P, DE LANGE JJ, PAULUS WJ, MUSTERS RJ: SIH - a novel lipophilic iron chelator - protects $\mathrm{H} 9 \mathrm{c} 2$ cardiomyoblasts from oxidative stress induced mitochondrial injury and cell death. J Mol Cell Cardiol 39: 345-354, 2005.

ŠIMŮNEK T, KLIMTOVÁ I, KAPLANOVÁ J, MAZUROVÁ Y, ADAMCOVÁ M, ŠTĚRBA M, HRDINA R, GERŠL V: Rabbit model for in vivo study of anthracycline-induced heart failure and for the evaluation of protective agents. Eur J Heart Fail 6: 377-387, 2004.

ŠTĚRBA M, POPELOVÁ O, ŠIMU゚NEK T, MAZUROVÁ Y, POTÁČOVÁ A, ADAMCOVÁ M, KAISEROVÁ H, POŇKA P, GERŠL V: Cardioprotective effects of a novel iron chelator, pyridoxal 2-chlorobenzoyl hydrazone, in the rabbit model of daunorubicin-induced cardiotoxicity. J Pharmacol Exp Ther 319: 1336-1347, 2006.

ŠTĚRBA M, ŠIMŮNEK T, MAZUROVÁ Y, ADAMCOVÁ M, POPELOVÁ O, KAPLANOVÁ J, POŇKA P, GERŠL $\mathrm{V}$ : Safety and tolerability of repeated administration of pyridoxal 2-chlorobenzoyl hydrazone in rabbits. Hum Exp Toxicol 24: 581-589, 2005.

SWAIN SM, VICI P. The current and future role of dexrazoxane as a cardioprotectant in anthracycline treatment: expert panel review. J Cancer Res Clin Oncol 130: 1-7, 2004.

VAN ACKER SABE, KRAMER K, VOEST EE, GRIMBERGEN JA, ZHANG J, VAN DER VIJGH WJF, VAN ACKER FAA, GRIMBERGEN JA, VAN DER VIJGH WJF, BAST A: Doxorubicin-induced cardiotoxicity monitored by ECG in freely moving mice. A new model to test potential protectors. Cancer Chemother Pharmacol 38: 95$101,1996$.

\section{Corresponding author}

M. Adamcová, Department of Physiology, Faculty of Medicine, Charles University, Hradec Králové, Šimkova 870, 50038 Hradec Králové 1, Czech Republic. Fax: +420 495436 054. E-mail: adamcova@lfhk.cuni.cz 